\title{
Investigation of structural and tribological properties of duplex surface treated pure titanium
}

\author{
İ. Çelik ${ }^{1 *}$, M. Karakan ${ }^{2}$ \\ ${ }^{1}$ Department of Mechanical Engineering, Faculty of Engineering, Gümüşhane University, 29100-Gümüşane, Turkey \\ ${ }^{2}$ Department of Mechanical Engineering, Faculty of Engineering, Atatürk University, 25240-Erzurum, Turkey
}

Received 14 March 2014, received in revised form 6 July 2014, accepted 5 January 2015

\begin{abstract}
Commercial pure titanium (CP-Ti) is used in many engineering fields because of its superior properties such as excellent corrosion resistance, high strength/weight ratio, and biocompatibility. However, it is not available at the desired rate, since the CP-Ti has poor wear resistance. For this reason, many surface treatments have been applied to improve the poor tribological properties of the CP-Ti. In this study, duplex surface treatments, which are the combination of treatments of electroless $\mathrm{Ni}-\mathrm{B}$ coating and plasma nitriding, were applied on the surfaces of the CP-Ti. Structural properties of the different surfaces of the treated materials were investigated using scanning electron microscopy (SEM) and X-ray diffraction (XRD). Microhardness measurements were made for the determination of mechanical properties and the pin-on-disk wear tests were made to determine the tribological properties. It was observed that poor wear resistance of the CP-Ti was improved with duplex surface treatments. The results showed that surface hardness, friction coefficient, and surface roughness of coated samples were better than of uncoated CP-Ti.
\end{abstract}

K e y words: titanium, wear, electroless Ni-B, plasma nitriding, duplex

\section{Introduction}

Titanium has a high affinity for oxygen. Hence, titanium-oxide $\left(\mathrm{TiO}_{2}\right)$ can form on the surface of the $\mathrm{CP}-\mathrm{Ti}$ in the wake of interaction between titanium and oxygen at low temperatures. In particular, the $\mathrm{CP}-\mathrm{Ti}$ is quickly oxidized when the temperature rises to a high level like $500^{\circ} \mathrm{C}$ [1-4]. The oxide film forming on the surface of CP-Ti at low temperatures has an unstable structure. This oxide layer provides resistance to corrosion for titanium. However, it causes to be poor wear resistance of the $\mathrm{CP}-\mathrm{Ti}$ in friction and contact applications. Thus, the oxide layer forming on the surface of titanium can be easily broken in applications, which are in contact with other materials. If broken oxide particles remain between the contact surfaces, they act abrasively and give rise to more oxide layers be separated from the surface. The oxide layer forms after re-interaction between oxygen and the substrate, were released with rupture of the oxide layer on the surface. This situation causes a contin- uation of this vicious cycle. This cycle is also known as oxidative wear, and the main reason for poor wear resistance of titanium $[5,6]$.

Wear damage is one of the major problems for materials used in engineering fields. It is not possible to eliminate this problem completely. However, the effect of wear damage of the surfaces of engineering materials can be reduced with suitable surface treatments. Surface treatments such as thermochemical treatments, ion implantation, electroplating, and electroless plating are widely used to solve this problem. When the literature is surveyed, it can be seen that a large number of surface treatments and coating methods have been applied to increase the wear resistance of the CP-Ti [7-14].

To improve wear resistance by applying the duplex treatments is the primary aim of the study. For the duplex treatments, two different techniques called electroless Ni-B coating and plasma nitriding were applied to the CP-Ti in this study. After each treatment, the mechanical, structural, and tribological proper-

*Corresponding author: tel.: +90-456-2337543; fax: +90-0456-2337446; e-mail address: ilh.celik@gmail.com 
Ta ble 1. Electroless Ni-B coating bath components and the coating parameters

\begin{tabular}{lc}
\hline Bath composition & $\left(\mathrm{g} \mathrm{l}^{-1}\right)$ \\
\hline Ethylenediamine $\left(\mathrm{NH}_{2}-\mathrm{CH}_{2}-\mathrm{CH}_{2}-\mathrm{NH}_{2}\right)$ & 90 \\
Lead nitrate $\mathrm{Pb}^{2+}\left(\mathrm{PbNO}_{3}\right)$ & 0.0145 \\
Nickel $(\mathrm{II})$ Chloride $\mathrm{Hexahydrate}\left(\mathrm{NiCl}_{2} \cdot 6 \mathrm{H}_{2} \mathrm{O}\right)$ & 10 \\
Sodium borohydride $(\mathrm{NaBH} 4)$ & 1.2 \\
Sodium hydroxide $(\mathrm{NaOH})$ & 90 \\
Coating parameters & 60 \\
Time $($ min $)$ & $95 \pm 0.3$ \\
Temperature $\left({ }^{\circ} \mathrm{C}\right)$ & $\geq 13.5$ \\
pH & \\
\hline
\end{tabular}

ties were investigated by SEM/XRD, microhardness tests, and friction/wear tests, respectively, and compared with the same results in the literature.

\section{Experimental details}

CP-Ti (Grade-2) with impurities of 0.006 wt.\% N, 0.002 wt. $\%$ H, 0.041 wt. $\%$ Fe, 0.15 wt.\% O, and 0.008 wt.\% $\mathrm{C}$ was used as the experimental material in this study. For surface treatments, specimens with the dimensions of $15 \mathrm{~mm} \times 15 \mathrm{~mm} \times 5 \mathrm{~mm}$ were produced from coarse-grained titanium. Afterward, the CP-Ti specimens were polished with $\mathrm{SiC}$ abrasive paper. The polished materials were conducted to the duplex surface treatment. This process consisted of two major sections. In the first section, the materials were coated by electroless Ni-B. Before electroless Ni-B coating, they were degreased with acetone to clean the surfaces. Then, they were rinsed with distilled water and dipped in $15 \% \mathrm{HCl}$ during $15 \mathrm{~s}$. After this process, they were carefully washed with distilled water and dried with a hot-air fan. Table 1 presents electroless $\mathrm{Ni}-\mathrm{B}$ coating bath components and coating parameters. Experiments about electroless Ni-B coating were carried out for $1 \mathrm{~h}$ at $95^{\circ} \mathrm{C}$ in this deposition bath. In the second section, before the plasma nitriding treatment, specimens were cleaned with hydrogen sputtering at a pressure of $5 \times 10^{2} \mathrm{~Pa}$ for $15 \mathrm{~min}$ to remove the foreign matter from the surfaces $[15,16]$, and then the plasma nitriding treatment was performed with a mixture of $75 \% \mathrm{~N}_{2}+25 \% \mathrm{H}_{2}$ under $5 \times 10^{2} \mathrm{~Pa}$ pressure at 500,600 , and $700^{\circ} \mathrm{C}$ for $4 \mathrm{~h}$ [17]. The specimens were cooled down inside the vacuum chamber up to room temperature after the nitridation.

The morphological properties of the duplex treated surfaces of the CP-Ti were examined using scanning electron microscopy (SEM). The phase structure of the duplex treated layer of the specimens was examined by X-ray diffraction technique. The XRD measurements were conducted at $\lambda=1.5405 \AA$ wavelength

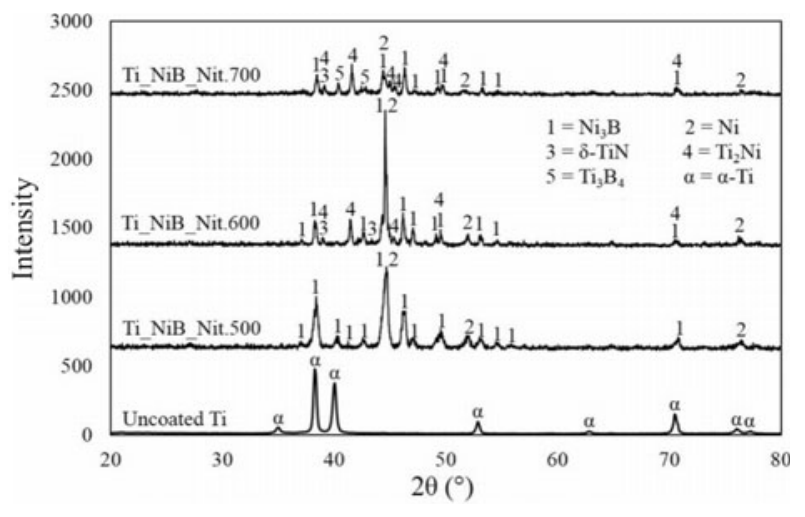

Fig. 1. The XRD patterns of the uncoated specimen and the duplex treated specimens.

with $2 \theta=20^{\circ}-80^{\circ}$ scanning angle and $2 \mathrm{deg} \mathrm{min}^{-1}$ scanning speed using $\mathrm{Cu} \mathrm{K} \alpha$ radiation. Hardness measurements of the duplex treated specimens were investigated using a Vickers microhardness tester operated at $\mathrm{HV}_{0.1}$.

The wear and friction tests were performed using a pin-on-disk type test rig with the samples having the dimensions of $15 \mathrm{~mm} \times 15 \mathrm{~mm} \times 5 \mathrm{~mm}$. The $\mathrm{Al}_{2} \mathrm{O}_{3}$ ball having a $6 \mathrm{~mm}$ diameter was used as a counter face. The friction and wear tests were conducted in the laboratory conditions with a temperature $23 \pm 2{ }^{\circ} \mathrm{C}$ and a relative humidity $47 \pm 3 \%$. The tests were carried out under an axial load of $2 \mathrm{~N}$ at a sliding speed of $36.65 \mathrm{~mm} \mathrm{~s}^{-1}$ and a sliding distance of $141 \mathrm{~m}$ $[15,18,19]$. To calculate the wear volume loss, the wear track profiles were recorded by a profilometer and then calculated by the superimposed profiles. Wear rate was obtained through the Eq. (1):

$$
W=V / F D,
$$

where $W$ is the wear rate $\left(\mu \mathrm{m}^{3} \mathrm{~N}^{-1} \mathrm{~m}^{-1}\right), V$ is the wear volume $\left(\mu \mathrm{m}^{3}\right), F$ is the axial load $(\mathrm{N})$, and $D$ is the sliding distance $(\mathrm{m})$. At least two samples for each case were tested, and the linear average values of them were taken into account. The worn surfaces of the samples in all conditions were examined using an SEM device.

\section{Results and discussion}

\subsection{XRD analysis}

Figure 1 shows the XRD patterns of the uncoated specimen and the duplex treated specimens. The XRD results indicate that $\alpha$-Ti peaks appeared in the spectra from uncoated specimen because the CP-Ti (Grade-2) has an alpha-titanium alloy.

ICDD 00-019-0834 card number for $\mathrm{Ni}_{3} \mathrm{~B}$ phase, 
ICDD 00-002-1221 card number for $\delta$-TiN phase, ICDD 01-072-0442 card number for $\mathrm{Ti}_{2} \mathrm{Ni}$ phase, ICDD 00-019-1364 card number for $\mathrm{Ti}_{3} \mathrm{~B}_{4}$ phase, and ICDD 01-070-1849 card number for $\mathrm{Ni}$ phase were used in the analysis of XRD patterns. Electroless $\mathrm{Ni}-\mathrm{B}$ coating has an amorphous structure [20, 21]. The structure of electroless Ni-B coating crystallized after the plasma nitriding treatments at the different temperatures same as heat treatment [22-25]. When $\mathrm{XRD}$ patterns were analyzed, it was observed that $\mathrm{Ni}_{3} \mathrm{~B}$ phase predominated in the structure of plasma nitrided CP-Ti which was initially coated electroless $\mathrm{Ni}-\mathrm{B}$ at $500^{\circ} \mathrm{C}$ (Ti_NiB_Nit.500). Moreover, Ni phase was determined at diffraction angles of $2 \theta=44.4^{\circ}$, $2 \theta=51.8^{\circ}$, and $2 \theta=76.4^{\circ}$. It was observed that $\mathrm{Ni}_{3} \mathrm{~B}$ phase also predominated in the structure of plasma nitrided CP-Ti which was initially coated electroless $\mathrm{Ni}-\mathrm{B}$ at $600^{\circ} \mathrm{C}$ (Ti_NiB_Nit.600). In addition to $\mathrm{Ni}_{3} \mathrm{~B}$ and $\mathrm{Ni}$ phases, $\mathrm{Ti}_{2} \mathrm{Ni}$ phase appeared at diffraction angles of $2 \theta=39.1^{\circ}, 2 \theta=41.4^{\circ}, 2 \theta=45.3^{\circ}, 2 \theta=49.5$, $2 \theta=70.5^{\circ}$ and $\delta$-TiN phase appeared at diffraction angles of $2 \theta=39.1^{\circ}$ and $2 \theta=43.5^{\circ}$. Furthermore, it was seen that peak intensity at a diffraction angle of $2 \theta=44.4^{\circ}$ was higher than plasma nitrided CP-Ti, which was coated electroless $\mathrm{Ni}-\mathrm{B}$, at $500^{\circ} \mathrm{C}$. It was figured out that the peak intensities of phases reduced at the surface structure of plasma nitrided CP-Ti at $700^{\circ} \mathrm{C}$ (Ti_NiB_Nit.700), which was coated electroless $\mathrm{Ni}-\mathrm{B}$ initially. Moreover, it was specified that the same peaks disappeared at Ti_NiB_Nit.600. Besides, $\mathrm{Ti}_{3} \mathrm{~B}_{4}$ phase appeared at diffraction angles of $2 \theta=40.4^{\circ}$, $2 \theta=41.7^{\circ}, 2 \theta=42.8^{\circ}$ and $\mathrm{Ti}_{2} \mathrm{Ni}$ phase appeared at diffraction angle of $2 \theta=45.1^{\circ}$.

\subsection{Surface analysis after the duplex treatments}

The surface morphologies and thicknesses of the duplex treated CP-Ti specimens were obtained by SEM micrographs shown in Figs. 2 and 3. These micrographs show clearly the layers of electroless Ni-B coating. Figure 2 shows that the surface morphology of the CP-Ti significantly changed depending on the applied duplex treatments. A typical cauliflower-like type structure was obtained on the surface of the CP-Ti with an electroless Ni-B coating applied as initial treatment. This structure was observed in [26-28]. The nodular cauliflower-like type structure also existed after the plasma nitriding treatments.

The coating thicknesses were measured about 4$5 \mu \mathrm{m}$. It was determined particularly that the diffusion layer formed about 150-160 $\mu \mathrm{m}$ after Ti_NiB_Nit.700 treatment (Fig. 3c). The hardness values of electroless Ni-B coated + plasma nitrided CP-Ti are shown in Fig. 4. As the temperature increases, the capability of diffusion also increases due to the basics of the diffusion process. As a result, as can be seen in Fig. 4, the
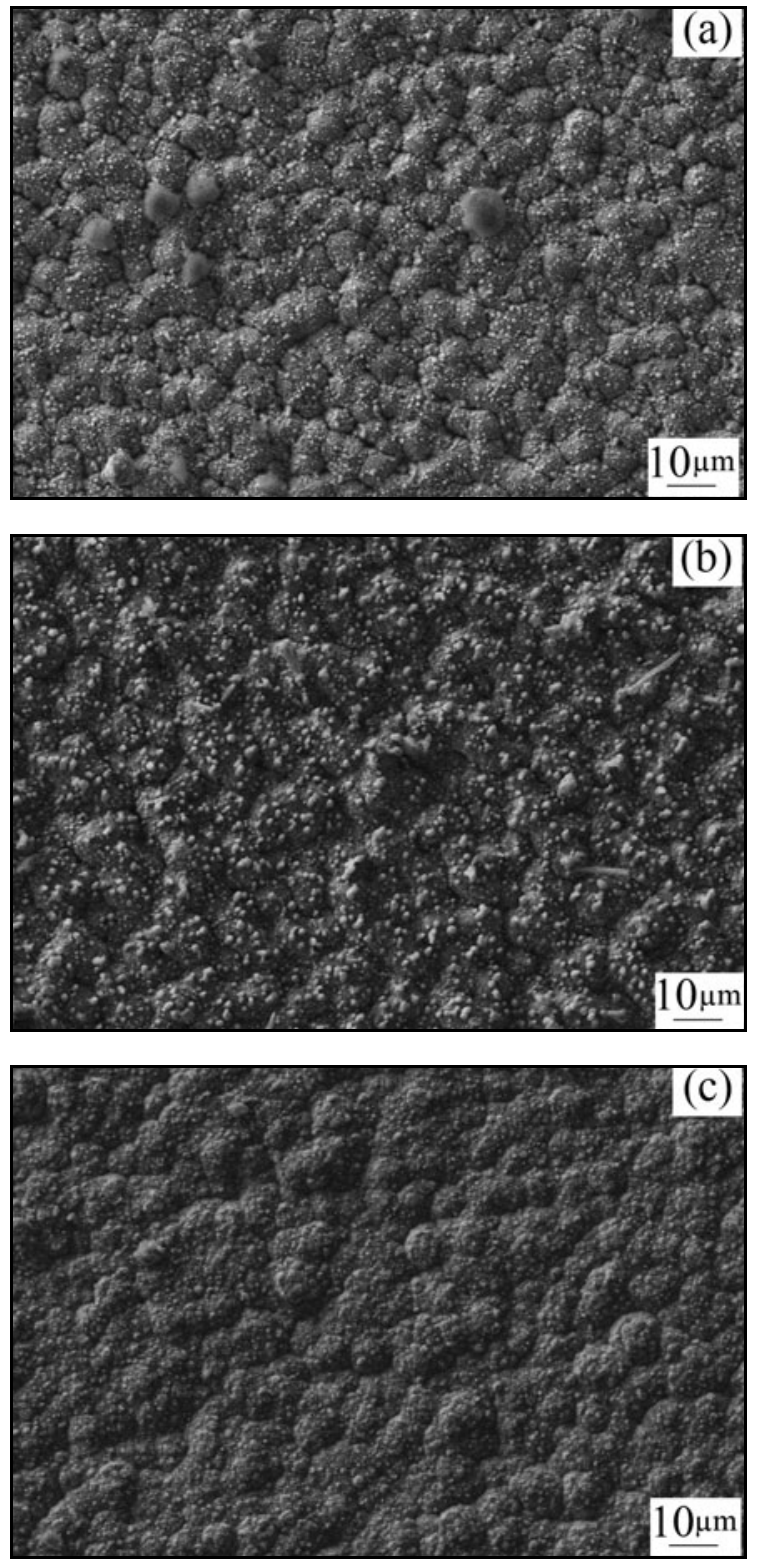

Fig. 2. Morphological surface SEM micrographs of the duplex treated CP-Ti: electroless Ni-B coated + plasma nitrided (a) at $500^{\circ} \mathrm{C},(\mathrm{b})$ at $600{ }^{\circ} \mathrm{C}$, and (c) at $700^{\circ} \mathrm{C}$.

formation of the diffusion layer causes the hardness to decrease down to the hardness of the structure [29]. Also, the duplex coating layer thicknesses are shown in Table 2.

\subsection{Tribological analysis}

The friction coefficients of the uncoated specimen and the duplex treated specimens are shown in Fig. 5. Average friction coefficient values of the duplex treated specimens are higher than average friction coefficient value of uncoated CP-Ti due to the duplex coating layer. While the friction coefficient 

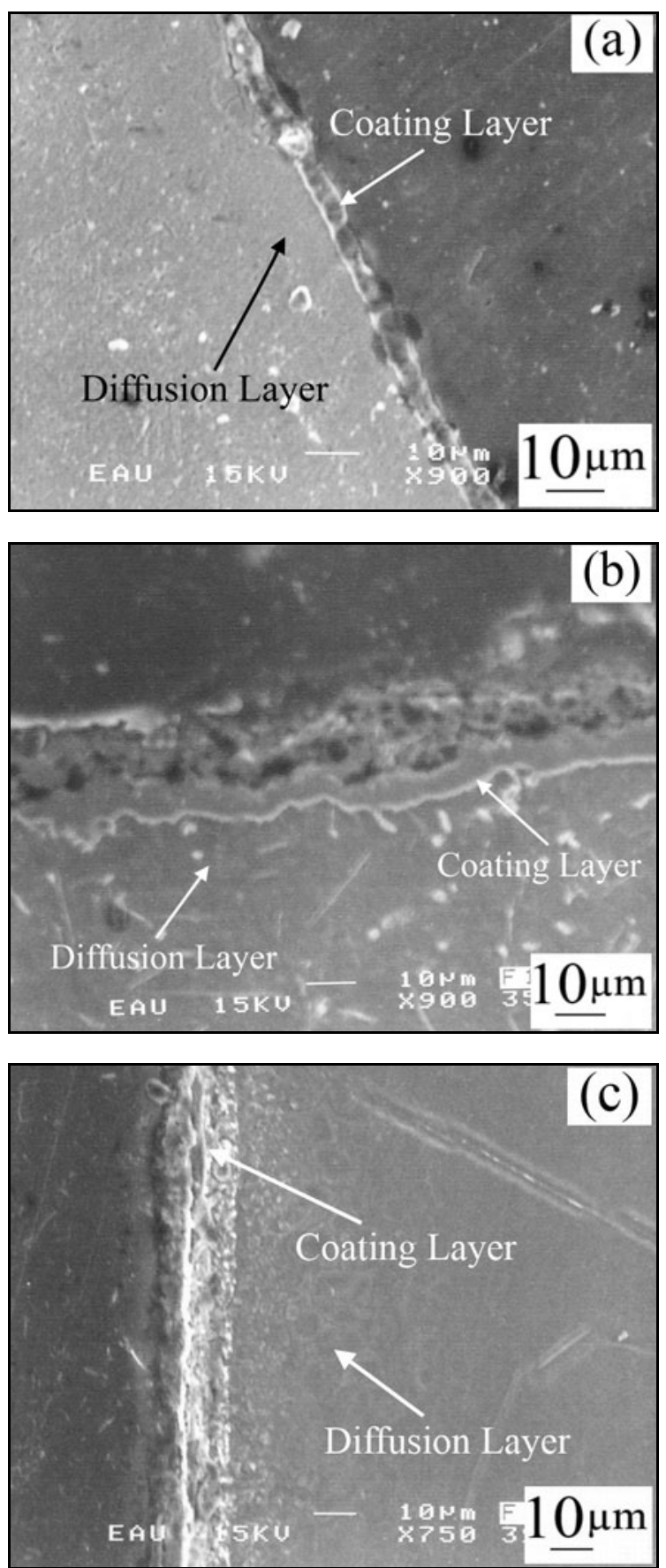

Fig. 3. Cross-section SEM micrographs of the duplex treated CP-Ti specimens: (a) Ti_NiB_Nit.500, (b) Ti_NiB_ Nit.600, and (c) Ti_NiB_Nit.700.

of the uncoated specimen was measured about 0.55, average friction coefficient values of Ti_NiB_Nit.500, Ti_NiB_Nit.600, and Ti_NiB_Nit.700 were found 0.57, 0.64 , and 0.60 , respectively (Table 3 ). As shown in Fig. 5, it was noticed that the friction coefficients of the CP-Ti substrate increased in the first $400 \mathrm{~s}$. Then the friction coefficient tried to stabilize and slightly oscillated at around 0.55. Structures of friction coef-

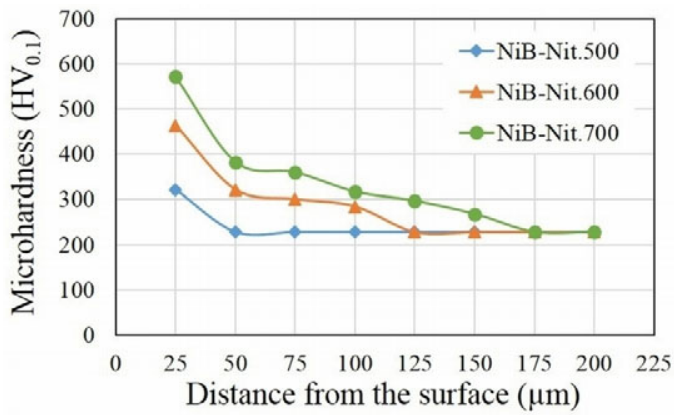

Fig. 4. Hardness distributions in cross-section of electroless $\mathrm{Ni}-\mathrm{B}$ coated + plasma nitrided CP-Ti.

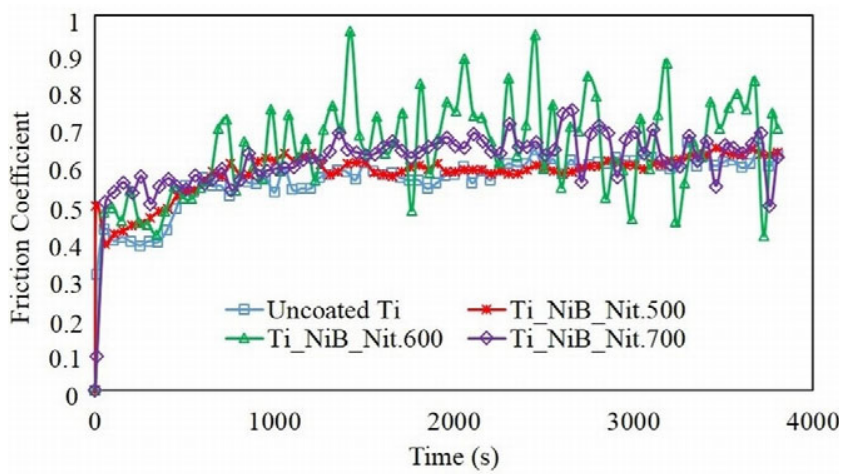

Fig. 5. Friction coefficients of uncoated CP-Ti and the duplex treated CP-Ti specimens.

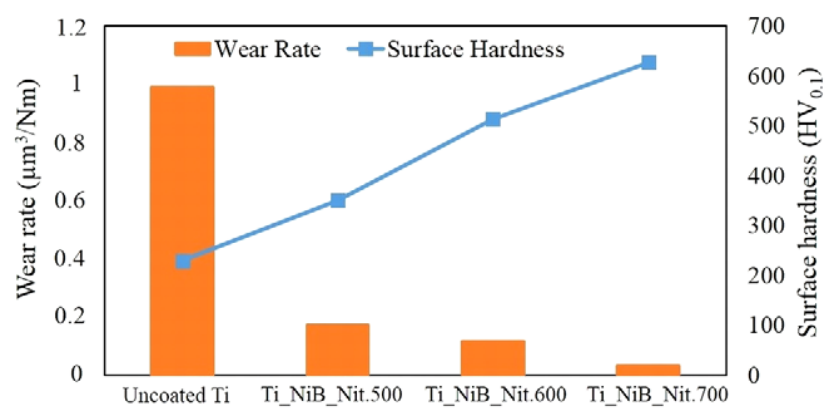

Fig. 6. Wear rate and surface hardness of uncoated CP-Ti and the duplex treated CP-Ti specimens.

ficient curves of Ti_NiB_Nit.500 and Ti_NiB_Nit.700 were stable. On the other hand, it was seen that structure of friction coefficient curve of Ti_NiB_Nit.600 was an unstable structure. It is thought that the surface roughness increased nine times as compared to the uncoated specimen, and it caused the unstable structure.

Figure 6 illustrates the relationship between wear rate and surface hardness of uncoated titanium, Ti_NiB_Nit.500, Ti_NiB_Nit.600, and Ti_NiB_Nit.700. The hardness of the $\mathrm{CP}-\mathrm{Ti}$ increased in all nitrid- 
Ta b le 2. Surface roughness, coating layer thickness, and diffusion layer thickness of the samples

\begin{tabular}{lccc}
\hline Specimen name & Coating layer thickness $(\mu \mathrm{m})$ & Diffusion layer thickness $(\mu \mathrm{m})$ & Surface roughness $(\mu \mathrm{m})$ \\
\hline Ti_NiB_Nit.500 & $4-5$ & $25-30$ & 0.45 \\
Ti_NiB_Nit.600 & $4-5$ & $100-110$ & 0.87 \\
Ti_NiB_Nit.700 & $4-5$ & $150-160$ & 0.61 \\
Uncoated Ti & - & - & 0.10 \\
\hline
\end{tabular}

Table 3. Wear rate, surface hardness, and friction coefficient of the samples

\begin{tabular}{lccc}
\hline Specimen name & Wear rate $\left(\mu \mathrm{m}^{3} \mathrm{~N}^{-1} \mathrm{~m}^{-1}\right)$ & Surface hardness, $\mathrm{HV}_{0.1}$ & Friction coefficient \\
\hline Ti_NiB_Nit.500 & $0.173 \pm 0.009$ & $350 \pm 9$ & 0.57 \\
Ti_NiB_Nit.600 & $0.117 \pm 0.007$ & $514 \pm 13$ & 0.64 \\
Ti_NiB_Nit.700 & $0.032 \pm 0.005$ & $627 \pm 10$ & 0.60 \\
Uncoated Ti & $0.991 \pm 0.021$ & $229 \pm 5$ & 0.55 \\
\hline
\end{tabular}
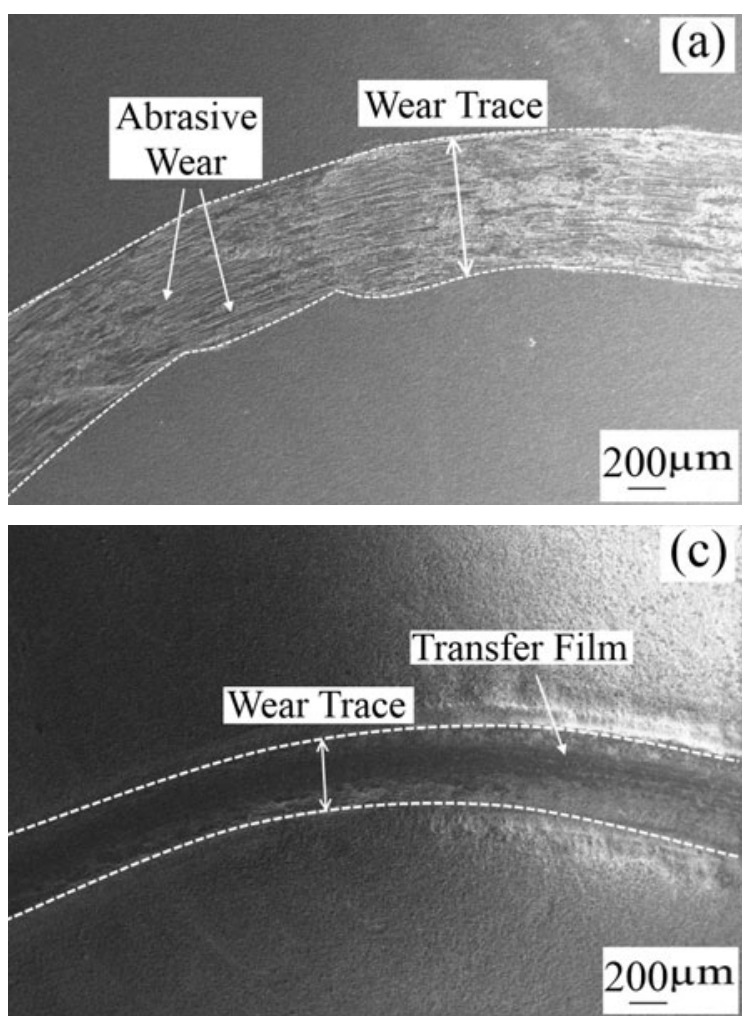

Fig. 7. SEM images of the worn surfaces of CP-Ti:

(d) Ti_NiB_Nit.700.
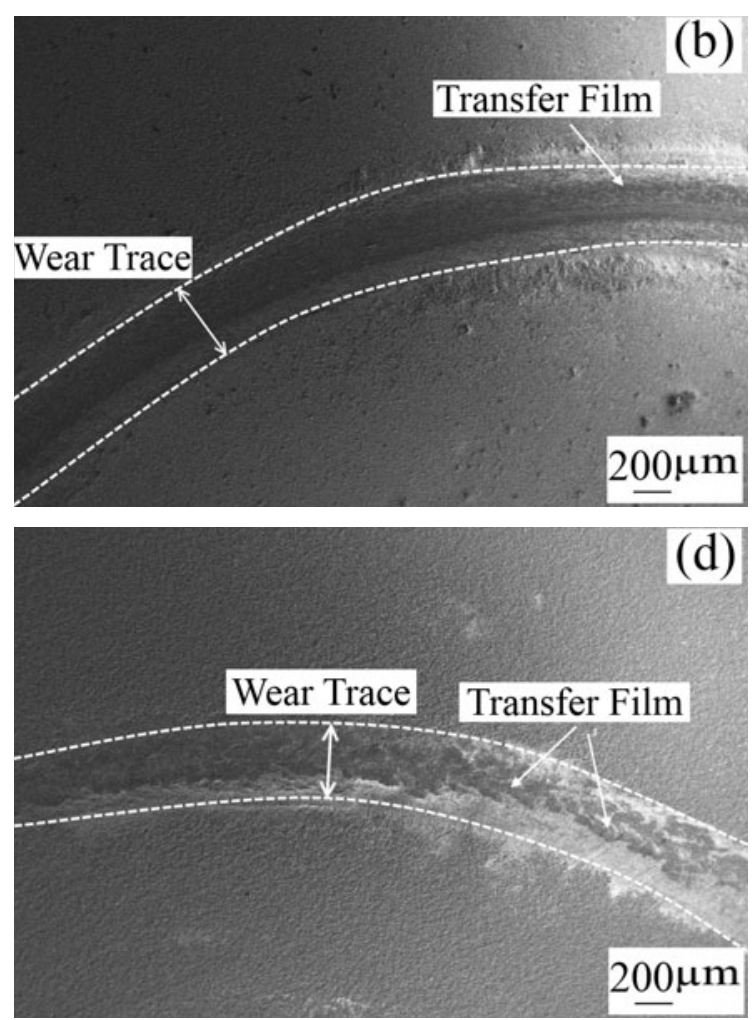

(b) Ti_NiB_Nit.500, (c) Ti_NiB_Nit.600,

ing conditions after electroless $\mathrm{Ni}-\mathrm{B}$, as a result of this increasing and the wear resistance improved ( $\mathrm{Ta}-$ ble 3). Amorphous Ni-B coating structure transforms to a crystalline structure at temperatures above $380^{\circ} \mathrm{C}$ [30]. Moreover, amorphous Ni-B coating structure transformed a crystalline structure, consisting of $\mathrm{Ni}_{3} \mathrm{~B}$ phase since plasma nitriding treatments were performed at temperatures above $500^{\circ} \mathrm{C}$. Furthermore, according to XRD analysis, after Ti_NiB_Nit.600 and Ti_NiB_Nit.700, there was a $\delta$-TiN phase in amor- phous Ni-B coating structure. This phase helped to increase the wear resistance and hardness. As seen in Fig. 6, while the hardness value of the CP-Ti increased, the wear rate of the CP-Ti decreased after the duplex treatments (Table 3 ).

SEM images of wear tracks of uncoated CP-Ti and the duplex treated specimens are given in Fig. 7. During the sliding process, the friction energy is usually used to produce heat, plastic deformation and promote further damages. The amount of tempera- 
ture produced by friction is sufficient to cause tribochemical reaction [31]. The worn surface of the CP-Ti has abrasive and adhesive types of wear, also known as intensive oxidation formation (white color particles). Besides, the wear track of uncoated CP-Ti is larger than all duplex treated specimens due to the easy deformation behavior of specimen without the hard duplex treated layer. This situation also gives rise to the low wear resistance or high wear rate. In this study, thin scratches generated by the abrasive debris were released as a result of breaks in a thin natural oxide film on uncoated CP-Ti (Fig. 7a). Transfer film occurred on the internal sides of wear tracks of Ti_NiB_Nit.500 and Ti_NiB_Nit.600. The wear residual was accumulated in the corners of wear tracks because of the thick and ruptured layer (Figs. 7b,c). When looking at the wear tracks, it is seen that the ball crushed the surface roughness during the wear test. The transfer film was formed due to crushing (Fig. 7d).

\section{Conclusions}

In this study, the duplex surface treatments were applied to the CP-Ti specimens using electroless Ni-B coating and the plasma nitriding.

In summary, the major findings can be summarized as follows:

$-\mathrm{Ni}_{3} \mathrm{~B}, \mathrm{Ti}_{3} \mathrm{~B}_{4}, \mathrm{Ti}_{2} \mathrm{Ni}$, and $\delta$-TiN phases formed on the CP-Ti as a result of the duplex surface treatments.

- The surface hardness and surface roughness of the CP-Ti specimens increased after the duplex surface treatments. Formation of the coating layer by the duplex treatment (Ti_NiB_Nit.700) caused about two times increase in surface hardness of the CP-Ti.

- The friction coefficient of the CP-Ti specimens changed with the duplex surface treatments. The highest friction coefficient was obtained in $\mathrm{Ti}_{-} \mathrm{NiB}_{-}$ Nit.600 about 0.64. However, the lowest friction coefficient was determined in Ti_NiB_Nit.500 about 0.57.

- It was determined that the wear resistance of the CP-Ti considerably improved with the duplex surface treatments. The narrowest wear tracks and the highest wear resistance were obtained in Ti_NiB_Nit.700 treatment.

\section{References}

[1] Hirose, A., Ueda, T., Kobayashi, K. F.: Mater. Sci. Eng. A, 160, 1993, p. 143. doi:10.1016/0921-5093(93)90507-B

[2] Dutta Majumdar, J., Weisheit, A., Mordike, B. L., Manna, I.: Mater. Sci. Eng. A, 266, 1999, p. 123. doi:10.1016/S0921-5093(99)00045-3

[3] Göttlicher, M., Rohnke, M., Helth, A., Leichtweiß, T., Gemming, T., Gebert, A., Eckert, J., Janek, J.: Acta
Biomater., 9, 2013, p. 9201. doi:10.1016/j.actbio.2013.07.015

[4] Umetsu, N., Sado, S., Ueda, K., Tajima, K., Narushima, T.: Mater. Trans., 54, 2013, p. 1302. doi:10.2320/matertrans.ME201315

[5] Budinski, K. G.: Wear, 151, 1991, p. 203. doi:10.1016/0043-1648(91)90249-T

[6] Purcek, G., Saray, O., Kul, O., Karaman, I., Yapici, G. G., Haouaoui, M., Maier, H. J.: Mater. Sci. Eng. A, 517, 2009, p. 97. doi:10.1016/j.msea.2009.03.054

[7] Vijayaraghavan, T. V., Bensalem, A.: J. Mater. Sci. Lett., 13, 1994, p. 1782. doi:10.1007/BF00776358

[8] Fu, Y., Yan, B., Loh, N. L., Sun, C. Q., Hing, P.: J. Mater. Sci., 34, 1999, p. 2269. doi:10.1023/A:1004569406535

[9] Yen, S. K., Lin, C. M.: Mater. Chem. Phys., 77, 2003, p. 70. doi:10.1016/S0254-0584(01)00562-4

[10] Yang, X., Lu, X., Zhang, Q., Zhang, X., Gu, Z., Chen, J.: Mater. Sci. Eng. C, 27, 2007, p. 781. doi:10.1016/j.msec.2006.08.011

[11] Çelik, I.: The Oxidation of Ultra-fine Grain Pure Titanium by Using Different Surface Processes. [MSc. Thesis]. Erzurum, Atatürk University 2010.

[12] Hu, J., Wang, Z., Guan, T., Gao, Y., Lv, X., Lin, X., Tang, C., Gao, B.: Surf. Coat. Technol., 204, 2010, p. 3833. doi:10.1016/j.surfcoat.2010.04.062

[13] Richard, C., Kowandy, C., Landoulsi, J., Geetha, M., Ramasawmy, H.: Int. J. Refract. Met. H., 28, 2010, p. 115. doi:10.1016/j.ijrmhm.2009.08.006

[14] Lin, N., Huang, X., Zou, J., Zhang, X., Qin, L., Fan, A., Tang, B.: Surf. Coat. Technol., 209, 2012, p. 212. doi:10.1016/j.surfcoat.2012.07.046

[15] Karakan, M., Denktaş, O.: Kovove Mater., 47, 2009, p. 367.

[16] Yetim, A. F., Yildiz, F., Alsaran, A., Çelik, A.: Kovove Mater., 46, 2008, p. 105.

[17] Albayrak, C., Hacisalihoglu, I., Vangolu, S. Y., Alsaran, A.: Wear, 302, 2013, p. 1642. doi:10.1016/j.wear.2013.01.064

[18] Yetim, A. F., Kovacı, H., Aslan, M., Çelik, A.: Wear, 301, 2013, p. 636. doi:10.1016/j.wear.2012.11.077

[19] Çomakl, O., Yetim, T., Çelik, A.: Surf. Coat. Technol., 246, 2014, p. 34 . doi:10.1016/j.surfcoat.2014.02.059

[20] Delaunois, F., Lienard, P.: Surf. Coat. Technol., 160, 2002, p. 239. doi:10.1016/S0257-8972(02)00415-2

[21] Lee, K. H., Chang, D., Kwon, S. C.: Electrochim. Acta, 50, 2005, p. 4538. doi:10.1016/j.electacta.2004.03.067

[22] Dervos, C. T., Novakovic, J., Vassiliou, P.: Mater. Lett., 58, 2004, p. 619. doi:10.1016/S0167-577X(03)00581-0

[23] Narayanan, T. S. N. S., Krishnaveni, K., Seshadri, S. K.: Mater. Chem. Phys., 82, 2003, p. 771. doi:10.1016/S0254-0584(03)00390-0

[24] Krishnaveni, K., Narayanan, T. S. N. S., Seshadri, S. K.: Surf. Coat. Technol., 190, 2005, p. 115. doi:10.1016/j.surfcoat.2004.01.038

[25] Bülbül, F., Çelik, İ.: J. Fac. Eng. Archit. Gazi Univ., 29, 2014, p. 89.(in Turkish)

[26] Anik, M., Körpe, E., Şen, E.: Surf. Coat. Technol., 202, 2008, p. 1718. doi:10.1016/j.surfcoat.2007.07.031

[27] Correa, E., Zuleta, A. A., Sepúlveda, M., Guerra, L., 
Castaño, J. G., Echeverría, F., Liu, H., Skeldon, P., Thompson, G. E.: Surf. Coat. Technol., 206, 2012, p. 3088. doi:10.1016/j.surfcoat.2011.12.023

[28] Bulbul, F.: Met. Mater. Int., 17, 2011, p. 67. doi:10.1007/s12540-011-0210-4

[29] Yetim, A. F., Yildiz, F., Vangolu, Y., Alsaran, A., Çelik, A: Wear, 267, 2009, p. 2179.

doi:10.1016/j.wear.2009.04.005
[30] Narayanan, T. S. N. S., Seshadri, S. K.: J. Alloy Compd., 365, 2004, p. 197. doi:10.1016/S0925-8388(03)00680-7

[31] Lin, N., Xie, F., Yang, H., Tian, W., Wang, H., Tang, T.: Appl. Surf. Sci., 258, 2012, p. 4960. $\underline{\text { doi:10.1016/j.apsusc.2012.01.128 }}$ 